\title{
New Approaches to Allogeneic Haematopoietic Cell Transplantation
}

\author{
Cemaleddin Ozturk and Sinem Civriz Bozdag \\ Department of Haematology, Ankara University Faculty of Medicine, Ankara, Turkey
}

DOl: https://doi.org/10.17925/OHR.2021.17.1.28

A logeneic haematopoietic cell transplantation is a potentially curative therapeutic option for all haematologic malignancies; however, it is a double-edged sword that may result in significant mortality and morbidity. In recent years, there have been groundbreaking advances in the availability of stem cell sources, emerging strategies for choosing the best donor, graft-versus-host disease (GVHD) prevention, and supportive care. Ultra-high-resolution next-generation sequencing technology has been introduced to obtain more information on human leucocyte antigen (HLA) typing, making it possible to access the best-matched donors. Functional HLA matching with T cell-epitopes 3 and 4, and the "delta functional distance" scoring system, may help with the graft-versus-leukaemia (GLV)-GVHD counterbalance, driving the immune reaction in the direction of GVL. More effective GVHD prophylaxis (post-transplant cyclophosphamide and anti-thymocyte globulin) makes it possible to reach a broader donor diversity, in terms of unrelated and haploidentical settings. Ex vivo stem cell expansion with numerous small molecules (StemRegenin 1, TAT-BMI1, nicotinamide, valproic acid) can improve engraftment and immune reconstitution rates in umbilical cord blood transplantation. Ruxolitinib, ibrutinib, vedolizumab, alpha-1 antitrypsin, and mesenchymal stromal cells have shown promising results in the treatment of acute and chronic GVHD. Letermovir and maribavir have also shown encouraging results in cytomegalovirus reactivation prophylaxis. This article summarizes the current state of art and paradigm shifts in allogeneic haematopoietic cell transplantation.

\section{Keywords}

Allogeneic haematopoietic cell transplantation, GVHD, HLA typing, conditioning regimen, stem cell source

Disclosures: Cemaleddin Ozturk and Sinem Civriz Bozdag have no financial or non-financial relationships or activities to declare in relation to this article.

Review Process: Double-blind peer review

Compliance with Ethics: All procedures were followed in accordance with the responsible committee on human experimentation and with the Helsinki Declaration of 1975 and subsequent revisions. Informed consent was received from the patient involved in this case study.

Authorship: All named authors meet the criteria of the International Committee of Medical Journal Editors for authorship for this manuscript, take responsibility for the integrity of the work as a whole and have given final approval for the version to be published.

Access: This article is freely accessible at touchONCOLOGY.com (c) Touch Medical Media 2020

Received: June 2, 2020

Accepted: December 17, 2020

Published Online: 25 May 2021

Citation: touchREVIEWS in Oncology \& Haematology. 2021;17(1):28-35

Corresponding Author: Cemaleddin Ozturk Department of Haematology Ankara University

Balkiraz Mah. Mamak Cd. No:12, 06620 Mamak/Ankara,

Turkey. E: cemaleddinozturk@gmail.com

Twitter: https://twitter.com/cemaleddinoztrk

Linkedin: https://www.linkedin.com/in/cemaleddin-

\%C3\%B6zt\%C3\%BCrk-58715350/

ORCID: 0000-0003-1591-6575

Support: No funding was received in

the publication of this article.
Allogeneic haematopoietic cell transplantation (allo-HCT) has a bi-faceted role in the treatment of haematopoietic malignancies. First, allo-HCT gives high-dose chemotherapy a chance to reduce the leukaemic burden; second, it allows graft-originated natural killer and T cells to initiate an adoptive immunotherapy effect against leukaemic cells via tumour-specific antigens, tumourassociated antigens and minor histocompatibility antigens. ${ }^{1-6}$ Allo-HCT plays a major role in the graft-versus-leukaemia (GVL) effect on residual leukaemic cells. ${ }^{7-9}$ The GVL effect can be clinically observed after donor lymphocyte infusions. In chronic myeloid leukaemia, approximately 70-90\% of patients can achieve complete remission after donor lymphocyte infusion. ${ }^{10,11}$ Although the GVL effect is mainly potent in chronic myeloid leukaemia and acute myeloid leukaemia (AML), it is restricted by graft-versus-host disease (GVHD). ${ }^{11-13}$ While it can be difficult to drive the immune reaction in a GVL direction rather than a GVHD direction, Johnson et al. established a method to promote the GVL effect without triggering GVHD in an animal study. ${ }^{14}$

The state of art in allo-HCT is based on balancing GVHD and the GVL effect. Selecting the best donor, prudent use of the immunosuppressive drugs for GVHD prevention and treatment, rapid engraftment, minimal toxicity with individualized conditioning regimens and supportive care are the fundamental elements to achieve this objective. In the last decade, with significant progress, allo-HCT has become a rational and curative option. ${ }^{15,16}$ The purpose of this review is to summarize the recent advances and paradigm shifts in allo-HCT.

\section{Changing from human leucocyte antigen analysis to functional human leucocyte antigen allele matching}

The identification of human leucocyte antigens (HLAs) to find a matched donor is the foremost step in allo-HCT. HLA-dependent interactions between lymphocytes and antigen-presenting cells play a fundamental role in bidirectional graft-host interplays. ${ }^{17}$ This relationship may lead to either graft rejection or GVHD. The traditional low-resolution method to identify HLA proteins was serological analysis using antigen-specific anti-sera. In the last two decades, HLA typing evolved from serological analysis to HLA polymorphism assays. Polymerase chain reaction (PCR) with sequencespecific oligonucleotides and sequence-specific primers was introduced, which revealed further details of amino acid differences. ${ }^{18,19}$ Currently, the Sanger sequencing method is accepted as the gold standard for HLA polymorphism analysis with the advantage of high-resolution tissue typing. ${ }^{20}$

Although Sanger sequencing and sequence-specific oligonucleotide methods are the elemental methods for HLA typing, next-generation sequencing (NGS) techniques have emerged in recent years, which provide more sensitive, faster, and more cost-effective information on HLA typing..$^{21-26}$ 
HLA typing with nanopore sequencing also offers more accurate throughputs in a faster manner than NGS methods such as Ion Torrent (Thermo Fisher Scientific, Waltham, MA, USA) and Miseq (Illumina, San Diego, CA, USA) ${ }^{27}$ Another method that can be used for HLA typing is RNA sequencing. ${ }^{26}$ This method supplies precise HLA typing results as well as killer immunoglobulin-like receptor mismatch, which may prevent relapse after allo-HCT. ${ }^{28,29}$ An 8/8 match for HLA-A, $-B$, - C or -DR loci has been preferred for related donors. Only one-third of the patients may have a fully matched sibling donor; ${ }^{30}$ therefore, clinicians refer to alternative donor sources, such as matched unrelated donors, haploidentical or umbilical cord blood donors.

The National Bone Marrow Program and the Center for International Blood and Marrow Transplant Research (CIBMTR) recommend DNAbased methods at high-resolution for HLA-A, HLA-B, HLA-C, HLA-DRB1 and HLA-DPB1 loci. HLA-DQB1, HLA-DRB3/4/5, HLA-DQA1 and HLA-DPA1 typing are underlined as a helpful strategy to avoid graft failure risk via determining possible HLA-sensitized patients, but not for routine testing for donor selections even if no impact on survival has been shown. ${ }^{31,32}$ HLA mismatches trigger T cell alloreactivity in distinct levels determined by T cell-epitope (TCE) mismatching. ${ }^{33}$ In recent years, in silico modelling has been developed to test functional HLA-DPB1 matching, such as TCE analysis (TCE3 and TCE4) and a scoring system named 'delta functional distance' derived from DPB1 TCE algorithm. ${ }^{34}$ These attempts are the first steps to achieve a significant breakthrough in the HLA typing paradigm.

The functional matching of HLA may contribute significantly to the counterbalance between GVL and GVHD. Consistently using these methods may improve allo-HCT outcomes in terms of overall survival (OS), non-relapse mortality, GVHD-free/relapse-free survival and risk of relapse. ${ }^{34-37}$

\section{Unrelated matched donor, unrelated cord blood donor or haploidentical related donor: which is better?}

Despite the advances in allo-HCT from alternative donor sources, HLAidentical sibling donor transplantation is considered the gold standard. ${ }^{38-41}$ In the USA, the probability of a 10/10 HLA matched sibling donor ranges from $13-51 \% .{ }^{42,43}$ Sibling match probability is 1.5 times lower in adults younger than 44 years compared with the older ones. ${ }^{42,43}$ In this regard, finding an alternative donor is indispensable. In a prospective study, Yakoub-Agha et al. showed that unrelated donor HCT has comparable outcomes with matched sibling donor HCT in terms of OS and non-relapse mortality. ${ }^{44}$ There are also several encouraging studies with retrospective analyses that corroborate the comparable outcomes of unrelated donor HCT and matched sibling donor HCT. ${ }^{45-47}$ Recently, however, unrelated donor allo-HCT rates have diminished, being replaced by haploidentical donor HCT. ${ }^{48,49}$ Access to an unrelated donor requires more time and funds. ${ }^{50,51}$ Donor search costs, transportation expenditure of cell product and increased use of anti-thymocyte globulin and defibrotide increase the cost of allo-HCT. Donor volunteering and the rapid availability of cell products in case of necessity during and after transplantation are the advantages of haploidentical transplantation.

Effective GVHD prophylaxis (post-transplant cyclophosphamide, antithymocyte globulin) and successful selection of the best donor have made haploidentical transplantation more preferable in recent years. Although there are no prospective randomized controlled trials, a retrospective cohort study in patients with AML has shown that haploidentical HCT has comparable outcomes with unrelated donor HCT, umbilical cord blood transplantation (UCBT) and even with matched sibling donor HCT. ${ }^{52,53}$ Even though haploidentical donors are not the firstline donor source for lymphomas, haploidentical transplantation with post-transplantation cyclophosphamide has been shown to result in similar outcomes as unrelated donor HCT and matched sibling donor HCT in Hodgkin lymphoma. ${ }^{54,55}$ For patients with thalassemia, the availability of a related donor is relatively low, as the donor candidate may suffer the same disease.

Allo-HCT from alternative donors, such as matched unrelated donors and haploidentical donors, is becoming increasingly available with each passing day. ${ }^{5,57}$ There is also a growing body of evidence to support haploidentical HCT in severe aplastic anaemia. ${ }^{58-60} \mathrm{~A}$ meta-analysis performed by the European Society for Blood and Marrow Transplantation (EBMT) Working Party, demonstrates that haploidentical HCT can be a feasible option for patients with severe aplastic anemia with acceptable engraftment success (engraftment rate $97.3 \%$, 95\% confidence interval [CI] 95.9-98.7), with relatively reduced complications (annual transplantrelated mortality [TRM] rate $6.7 \%, 95 \% \mathrm{Cl}$ 4.0-9.4). ${ }^{61}$ Although in recent years, chimeric antigen receptor T (CAR T) cell therapies have provide promising results in non-Hodgkin lymphoma, it is not plausible to say that allo-HCT will be superseded by CAR T-cell therapy. ${ }^{62,63}$

Data on the role of haploidentical HCT are scarce in patients with nonHodgkin lymphoma compared to AML and Hodgkin lymphoma. Kanate et al. also showed that post-transplant cyclophosphamide-based haploidentical HCT in non-Hodgkin lymphoma has comparable OS and non-relapse mortality outcomes in addition to lower chronic GVHD rates. ${ }^{64,65}$ Recently, Dreger et al. conducted a large-scale retrospective analysis to compare haploidentical HCT with unrelated donor HCT and matched sibling donor HCT in diffuse large B cell lymphoma. There was no significant difference between the groups in terms of OS, non-relapse mortality, and progression-free survival (PFS), but a lower incidence of chronic GVHD was seen in the haploidentical HCT group. ${ }^{64}$

UCBT can be an alternative donor source in case of unrelated donor unavailability. However, the number of UCBT procedures has decreased in recent years. ${ }^{50,66}$ The advantages of UCBT are that there is no need for HLA full match donor, the availability of rare HLA types, no need to perform harvest, and lower GVHD rates even in higher HLA mismatch. 30,67,68 The disadvantages include an increase in the possibility of graft failure and delay in immune reconstitution as a result of low CD34+ counts, especially for adult patients. Moreover, post-thaw stem-cell counts can be lowered to within the range of $1-25 \% .{ }^{69}$ Novel techniques are being tested for improving engraftment and immune reconstitution in UCBT. UCB ex vivo stem-cell expansion with numerous small molecules (StemRegenin 1, TAT-BMI1, nicotinamide, valproic acid, sitagliptin) have been introduced. ${ }^{70-74}$ Hypoxia culturing, co-culture with mesenchymal stem cells, co-infusion with mesenchymal stem cell, double UCBT and co-infusion with third-party selected $\mathrm{CD}_{3} 4^{+}$haploidentical stem cells are other techniques that can enhance outcomes of UCBT. . $^{7-78}$ However, further confirmatory clinical trials are required for these promising stem cell expansion methods. Due to the lack of randomized controlled trials comparing haploidentical HCT, unrelated donor transplant and UCBT, regional factors and the experience of the transplant centres mostly come to the fore in the preference of donor sources.

\section{Conditioning regimens for allogeneic haematopoietic stem cell transplantation}

When choosing a conditioning regimen, the key factors are the type and state of the disease as well as the patient's comorbidities. Although myeloablative regimens have been preferred in young, fit patients, 
reduced-intensity conditioning (RIC) regimens have been introduced for elderly, unfit patients with comorbidities. The consideration of the GVL effect of allo-HCT has been the rational basis of RIC regimens. ${ }^{79}$ The optimal conditioning regimen for patients older than 50 years remains controversial due to the lack of prospective randomized controlled studies. ${ }^{80,81}$

In young patients with AML or myelodysplastic syndrome, myeloablative regimens have been compared with RIC regimens. A phase III randomized controlled study showed better, but not statistically significant, OS at 18 months with myeloablative regimens compared to RIC regimens (77.5 versus $67.7 \%$, respectively; $p=0.07)$. Higher relapse rates were observed in $\mathrm{RIC}$ regimens (67.8\% and $47.3 \%$, respectively; $\mathrm{p}<0.01$ ), and TRM was $15.8 \%(n=22)$ in the myeloablative group and $4.4 \%(n=8)$ in the RIC group $(\mathrm{p}=0.02) .{ }^{82}$ In another study, the RIC and myeloablative regimens showed no significant differences in terms of OS (31\% versus $24 \%$, respectively; $\mathrm{p}=0.10$ ), 10 -year non-relapse mortality ( $16 \%$ versus $26 \%$, respectively; $p=0.10$ ), and 10-year disease-free survival ( $55 \%$ versus $43 \%$, respectively; $\mathrm{p}=0.19$ ) in patients with intermediate and high-risk AML between 18 and 60 years old. ${ }^{83}$

In elderly patients with AML, promising long-term outcomes with more widely used regimens, like fludarabine or busulfan, have been shown. Recent data have shown more favourable outcomes in terms of PFS and GVHD-free/relapse-free survival with fludarabine $160 \mathrm{mg} / \mathrm{m}^{2}$ + melphalan $100 \mathrm{mg} / \mathrm{m}^{2}$ when compared with fludarabine $160 \mathrm{mg} / \mathrm{m}^{2}$ + melphalan 140 $\mathrm{mg} / \mathrm{m}^{2}$, fludarabine (with or without clofarabine) $160 \mathrm{mg} / \mathrm{m}^{2}$ + busulfan $\times 4$ days (area under curve $[\mathrm{AUC}] \geq 5,000 \mathrm{\mu mol} / \mathrm{min} /$ day), and fludarabine (with or without clofarabine) $160 \mathrm{mg} / \mathrm{m}^{2}$ + busulfan $\times 4$ days (AUC 4,000 $\mu \mathrm{mol} /$ min/day). Non-relapse mortality at 3 years was $19 \%, 39 \%, 35 \%$ and $21 \%$, respectively $(p=0.06)$, and 3-year relapse rates were $32 \%, 32 \% 30 \%$, and $55 \%$, respectively $(p=0.003) .{ }^{84} \mathrm{~A}$ study that compared total body irradiation (TBI)-based and busulfan-based conditioning in AML showed no significant difference between the treatment groups in terms of the 2-year OS $(64 \%$ versus $84 \%$, $p=0.73$ ), PFS ( $52 \%$ versus $53 \%$, $p=0.96)$, RFS ( $76 \%$ versus $84 \%$, $\mathrm{p}=0.95)$, and non-relapse mortality ( $27 \%$ versus $47 \%, p=0.56) .{ }^{85}$ Clift et al. compared busulfan + cyclophosphamide with cyclophosphamide + TBI as a conditioning regimen in AML. ${ }^{86}$ There was no difference between study arms in terms of OS, PFS and non-relapse mortality.

In recent years, the body of literature has increased concerning minimal/ measurable residual disease (MRD), which can be determined with multiparametric flow cytometry, PCR or NGS techniques. However, it is not possible to perform molecular MRD analysis for around 60\% of patients with AML, due to a lack of suitable markers for real-time PCR. ${ }^{87}$ In order to address this limitation, Thol et al. developed an NGS MRD technique that was able to identify a suitable marker in $93 \%$ of patients sequenced at the time of diagnosis. ${ }^{88}$ Patients who have morphologic complete remission after AML treatment, but ongoing MRD positivity before allo-HCT, have lower OS and PFS outcomes compared with patients who achieve MRD negativity. ${ }^{89,90}$

MRD assessment before transplantation can also help determine which patients may benefit from allo-HCT. The GIMEMA AML1310 study was conducted to examine the clinical outcome of risk-adapted post-remission therapy based on MRD assessment with PCR and multiparametric flow cytometry. In this study, MRD-driven transplantation improved the OS and DFS outcomes of intermediate-risk patients to levels similar to those of favourable risk. ${ }^{91}$ Shah et al. conducted a study to examine the MRD analysis after allo-HCT in patients with AML. The study showed that detection of MRD positivity in the early post-transplantation phase portends a higher relapse risk. ${ }^{92}$ Although allo-HCT can be a curative option for AML, the relapse incidence and mortality rates remain high, making it reasonable to seek an optimal post-transplant maintenance approach.

The RELAZA2 study is a phase II, single-arm study set out to clarify the outcomes of azacitidine maintenance in patients with myelodysplastic syndrome or AML with MRD positivity after allo-HCT or conventional chemotherapy. In this study, $58 \%(95 \% \mathrm{Cl} 44-72)$ of patients who were MRD-positive were relapse-free with azacitidine maintenance $(p<0.0001) .{ }^{93}$ In another major study, SORMAIN, which set out to examine the outcomes of sorafenib maintenance after allo-HCT in FLT3-positive patients with AML with or without MRD positivity, showed that sorafenib maintenance significantly reduced the risk of death and relapse (hazard ratio [HR] 0.39; 95\% Cl 0.18-0.85). ${ }^{94}$ Furthermore, Schlenk et al. demonstrated that single-agent maintenance of midostaurin in patients with FLT3-positive AML after allo-HCT is safe and feasible. In this study, starting the midostaurin maintenance at day 100 post-transplant had better event-free survival and OS outcomes compared to within 100 days after transplant. ${ }^{95}$ An ongoing phase III randomized, placebo-controlled multicentre study is being conducted to test the outcomes of gilteritinib maintenance after allo-HCT in FLT3-positive patients with AML, the results are not yet published (ClinicalTrials.gov Identifier: NCT02997202). ${ }^{96}$

RIC regimens also can be feasible in older patients with acute lymphoblastic leukaemia (ALL). In a retrospective study, Mohty et al. found that there was no association between the type of conditioning regimen (myeloablative versus $\mathrm{RIC}$ ) and leukaemia-free survival $(\mathrm{p}=0.23, \mathrm{HR}=0.84) .{ }^{97}$ Marks et al. compared full-intensity and RIC regimens in older patients with ALL; they showed that the intensity of the conditioning regimen did not affect outcomes of TRM $(p=0.92)$ and relapse risk $(p=0.14) .{ }^{98}$

Although TBI has been accepted as the key component of conditioning regimens in $A L L$, rather than $A M L$, acute and delayed toxicity of TBI remains as a substantial challenge. CIBMTR data showed a higher relapse rate (38\% versus $27 \%$, respectively; $p=0.007$ ) but similar survival rates ( $57 \%$ versus $53 \%$, respectively; $p=0.35$ ) with busulfan-based conditioning regimens compared with TBI-based regimens in ALL. ${ }^{99}$ In a Korean study, TBI-based conditioning regimens showed favourable outcomes in young adults independent of acute leukaemia subtype $(p=0.005) .{ }^{100} \mathrm{In}$ patients younger than 40 years, TBI provides better 5 -year OS $(55.1 \%$, $\mathrm{p}=0.023)$ and disease-free survival (DFS) $(48.6 \%, p=0.020)$ outcomes than busulfan-based conditioning regimens. ${ }^{101}$ The EBMT Acute Leukaemia Working Party showed that the combination of TBI with etoposide is as effective as combination with cyclophosphamide (HR 0.62, $\mathrm{p}=0.04){ }^{102}$ In a retrospective analysis from Japan, intravenous busulfan + cyclophosphamide had comparable outcomes with TBI-based regimens in $\mathrm{ALL} .{ }^{103} \mathrm{RIC}$ regimens in ALL have increased in recent years and mostly formed from chemotherapeutics only. ${ }^{104}$

Recent studies confirm that allo-HCT provides a clinical benefit in terms of relapse risk and survival in patients with Philadelphia chromosome (Ph)-negative and Ph-positive ALL who have ongoing MRD positivity after induction chemotherapy. ${ }^{105,106}$ Dhédin et al. demonstrated that allo-HCT improved relapse-free survival in patients with Ph-negative B-cell precursor ALL who had post-induction MRD positivity. ${ }^{107} \mathrm{~A}$ retrospective Chinese study, in patients with Ph-positive $A L L$, found that pre-transplantation MRD positivity resulted in a higher cumulative incidence of relapse compared with MRD negativity (26.1\% versus $12.1 \%$, $\mathrm{p}=0.009$ ); however, non-relapse mortality, OS and leukaemia-free survival outcomes were comparable. ${ }^{108}$ Although MRD is a broadly accepted key prognostic indicator in B-cell ALL, it is understudied in T-cell ALL. Modvig et al. analyzed the effect of flow cytometry-based MRD assessment on 
the outcomes of patients with T-cell ALL. They showed that patients who have flow cytometry-based MRD $\geq 10^{-3}$ at the end of the induction have a higher HR for relapse compared to flow cytometry-based MRD $\leq 10^{-3} .106$ There has been increasing convincing evidence to substantiate MRDguided allo-HCT decision-making.

The long-term outcomes of RIC, myeloablative and non-myeloablative conditioning regimens have been compared in large B-cell lymphoma, and results showed that rates of GVHD were similar between the groups. Higher 5-year non-relapse mortality was found in the myeloablative regimen compared to RIC and non-myeloablative (56\% versus $47 \%$ versus $36 \%$, respectively; $\mathrm{p}=0.007$ ) and 5 -year relapse/progression was lower in the myeloablative regimen compared to RIC and non-myeloablative (26\% versus $38 \%$ versus $40 \%$, respectively; $p=0.031$ ). There were no significant differences in survival at years 1, 3 and 5 between the myeloablative, RIC and non-myeloablative regimens (respective results at 1 year: $38 \%$ versus $46 \%$ versus $45 \%$; 3 years: $21 \%$ versus $27 \%$ versus $29 \%$; and 5 years: $18 \%$ versus $20 \%$ versus $26 \%) .{ }^{109}$

In RIC regimens, the importance of lymphoma histology on the outcomes of HCT has been emphasized in studies. Patients with indolent nonHodgkin lymphoma who underwent allo-HCT with RIC regimens have been found to have favourable outcomes (HR 0.4, $p=0.045$ ) compared to those with Hodgkin lymphoma and aggressive non-Hodgkin lymphoma. ${ }^{110,111}$ A systematic review/meta-analysis in chronic lymphocytic leukaemia, showed that RIC regimens are more commonly used, despite a lack of randomized studies in myeloablative and RIC regimens. ${ }^{112}$ The Chronic Lymphocytic Leukaemia Working Party of EBMT reported no difference in 5-year OS, event-free survival and non-relapse mortality outcomes of non-myeloablative and RIC regimens (RIC: $46 \%, 38 \%, 35 \%$; and nonmyeloablative: $52 \%, 43 \%, 32 \%$, respectively). ${ }^{113}$

The incidence of allo-HCT has decreased since the introduction of tyrosine kinase inhibitors for chronic myeloid leukaemia. ${ }^{114}$ Despite the excellent outcomes of tyrosine kinase inhibitors in chronic myeloid leukaemia, allo-HCT holds its place in the treatment of the multiple tyrosine kinaseinhibitor-resistant conditions. RIC regimens have been preferred due to the strong GVL effect in chronic myeloid leukaemia. ${ }^{115,116} \mathrm{~A}$ study based on the CIBMTR database shows that there is no significant difference in adult patients with chronic myeloid leukaemia who underwent alloHCT with myeloablative and RIC regimens in terms of OS, non-relapse mortality and leukaemia-free survival. However, RIC regimens provided lower chronic GVHD rates (HR 0.77; $\mathrm{p}=0.02) .{ }^{117}$

Despite of the fact that allo-HCT is associated with substantial treatment-related morbidity and mortality, it remains the only curative therapeutic option for primary and secondary myelofibrosis. ${ }^{118}$ Patients with intermediate-2 and high-risk myelofibrosis score according to the International Prognostic Scoring System can be a candidate for alloHCT. Fludarabine-based RIC regimens have been widely used with promising event-free survival and OS rates. ${ }^{119}$ In a study that compared busulfan + fludarabine, fludarabine + melphalan and fludarabine + BCNU (bis-chlorethyl-nitroso-urea) + melphalan-based RIC regimens in patients with myelofibrosis, there were no differences between the treatment arms in terms of survival $(p=0.65)$, grade $2-4$ acute GVHD $(47 \%, 68 \%$ and $68 \%$, respectively; $\mathrm{p}=0.31)$, relapse $(29 \%, 14 \%$ and $9 \%$, respectively; $\mathrm{p}=0.21)$, and non-relapse mortality $(29 \%, 41 \%$ and $27 \%$, respectively; $p=0.32$ ). ${ }^{120}$ Kröger et al. analyzed the transplantation outcomes of patients with primary and secondary myelofibrosis who underwent allo-HCT with a busulfan $(10 \mathrm{mg} / \mathrm{kg})$ + fludarabine (180 mg/m²)-based RIC regimen. ${ }^{121}$ In this prospective phase II trial, the RIC regimen showed 51\% 5-year event-free survival and 67\% OS. The results also showed that age $>55$ years (HR 2.7; $p=0.02$ ) and HLA mismatch (HR 3.04; $p=0.006$ ) are risk factors for survival.

In severe aplastic anaemia, allo-HCT from a matched sibling donor is the first-line treatment choice in patients younger than 50 years old. The standard conditioning regimen for matched sibling donor transplantation is cyclophosphamide $(200 \mathrm{mg} / \mathrm{kg}$ ) and anti-thymocyte globulin.122 In immunosuppressive therapy-refractory patients who are older than 30 years, fludarabine can be a less toxic alternative option to cyclophosphamide. ${ }^{23}$ Maury et al. demonstrated survival benefit with a fludarabine-based conditioning regimen compared with cyclophosphamide-based conditioning $(p=0.04){ }^{124}$ The survival benefit might be related to lower graft failure rates $(0 \%$ versus $11 \%, p=0.09)$ in the fludarabine arm.

In thalassemia major, busulfan + cyclophosphamide-based conditioning regimens have been accepted as the gold standard for matched sibling donor allo-HCT, for decades. ${ }^{125}$ Disease-specific conditions, such as haemochromatosis secondary to multiple transfusions, smooth the way for the hepatotoxicity of the busulfan + cyclophosphamide regimen. Mathews et al. demonstrated that a treosulfan-based regimen (treosulfan + thiotepa + fludarabine) reduced the incidence of sinusoidal obstruction syndrome (78\% to $30 \% ; p=0.000$ ) and TRM ( $46 \%$ to $13 \% ; p=0.005$ ) in highrisk patients with thalassemia major. ${ }^{126}$

In primary immunodeficiency diseases, conditioning regimens may not be needed if matched sibling bone marrow sources are preferred. ${ }^{127,128}$ Dvorak et al. demonstrated that unrelated donor transplantation can be performed without a conditioning regimen, and showed comparable OS ( $71 \%$ versus $92 \%, p<0.01$ ), acute GVHD ( $50 \%$ versus $39 \%, p<0.01)$, chronic GVHD ( $22 \%$ versus $5 \%, p<0.01)$, and event-free survival outcomes with matched sibling donor HCT. ${ }^{129}$ The Inborn Errors Working Party recommends fludarabine + busulfan or fludarabine + treosulfan-based conditioning regimens. ${ }^{130}$

Despite its effectiveness, physicians search for alternatives to TBI because of secondary malignancies and organ damage, such as pneumonitis, infertility and veno-occlusive disease. ${ }^{131}$ In this regard, targeted radiotherapy via radiolabeled monoclonal antibodies can spare the vital organs and give the advantage of potentiating the effective radiotherapy dosing. In a recent phase I study, vo et al. reported the efficacy of allo-HCT with yttrium-90-labeled CD45-targeted radiotherapy-based RIC in elderly patients with active leukaemia or myelodysplastic syndrome. ${ }^{132}$ The yttrium-90-labeled CD45-targeted radiotherapy-based combined conditioning regimen resulted in complete remission for $87 \%$ of the patients. One-year relapse rate and 2 -year OS were $41 \%$ and $46 \%$, respectively. Bouabdallahet al. conducted a phase II clinical trial to investigate the effects of yttrium-90 ibritumomab tiuxetan as part of RIC allo-HCT in high-risk patients with non-Hodgkin lymphoma. In this study, both 2-year OS and event-free survival were $80 \%{ }^{133}$

\section{Graft-versus-host disease prophylaxis}

GVHD is one of the major complications of allo-HCT. Traditional GVHD prophylaxis with calcineurin inhibitors has been insufficient, especially since the introduction of new allo-HCT modalities. ${ }^{134}$ Approximately 13 years ago, Storb et al. showed that cyclosporine and methotrexate are associated with lower acute GVHD rates (33\% versus 54\%, $\mathrm{p}=0.014$ ) compared with cyclosporine alone. ${ }^{135}$ To date, calcineurin-based GVHD prophylaxis is widely accepted as the gold standard. 
Although there are no prospective randomized studies, several researchers have attempted modalities of calcineurin-free GVHD prophylaxis. ${ }^{136-138}$ A phase II prospective study, conducted by Bejanyan et al., compared cyclosporine + mycophenolate mofetil combination with sirolimus + mycophenolate mofetil combination. ${ }^{138}$ There were no significant influences on the risk of acute GVHD, OS and PFS with calcineurin-free prophylaxis; however, there were significant reductions in thrombotic microangiopathy and infection rates. Recently, a metaanalysis that evaluated cyclosporine + methotrexate versus tacrolimus + methotrexate showed that tacrolimus + methotrexate resulted in lower grade $2-4$ acute GVHD (odds ratio 0.42; $\mathrm{p}<0.0001$ ), chronic GVHD (odds ratio $0.79 ; p=0.015$ ), non-relapse mortality (odds ratio $0.62 ; p=0.03$ ), and improved OS (odds ratio 1.3; $p<0.0001$ ) outcomes. ${ }^{139}$

Mycophenolate mofetil can also be combined with calcineurin inhibitors instead of methotrexate, especially in non-myeloablative conditioning regimens. ${ }^{140} \mathrm{Abatacept}$, which is an inhibitory protein of T cell co-stimulation, was tested in a phase I trial for GVHD prophylaxis in combination with tacrolimus and methotrexate. Combination of abatacept for GVHD prophylaxis was found safe and the rate of grade 2-4 acute GVHD was $28.6 \%$ at day $100 .{ }^{141}$ Similarly, a retrospective study set out to determine whether abatacept + cyclosporine + methylprednisolone is effective compared to standard GVHD prophylaxis with tacrolimus + mycophenolate mofetil in patients with beta-thalassemia. The study showed that none of the patients in the abatacept combination group experienced grade $3 / 4$ acute GVHD (0\% versus $50 \%, p=0.001)$ or graft failure. ${ }^{142}$

To investigate the role of CXCR5 blocking with maraviroc in GHVD prophylaxis, Reshef et al. carried out a phase II trial which demonstrated that grade $3 / 4$ acute GVHD at day 180 and 1-year moderate to severe chronic GVHD were $5 \pm 4 \%$ and $8 \pm 5 \%$, respectively. ${ }^{143} \mathrm{~A}$ meta-analysis indicated that mesenchymal stromal cells in the GVHD prophylaxis setting improved OS rate and decreased the grade 4 acute GVHD. ${ }^{144} \mathrm{~A}$ prospective study evaluated the combination of ruxolitinib and posttransplant cyclophosphamide for GVHD prophylaxis in patients with primary or secondary myelofibrosis. The rate of acute GVHD grade $2-4$ and grade $3 / 4$ were $25 \%$ and $15 \%$, respectively. From a total of 20 patients, 11 (55\%) experienced severe poor graft function and one patient primary graft failure. ${ }^{145}$ Luznik et al. studied the bidirectional cytotoxic T-cell tolerance effect of post-transplant cyclophosphamide. They found that it is efficient in preventing GVHD by selectively eliminating $T$ cells, and can result in durable engraftment. ${ }^{146}$

Consideration of post-transplant cyclophosphamide on ameliorating the detrimental effect of HLA disparity has been highly encouraged in the haploidentical allo-HCT setting. It has also been found as a rational option in matched unrelated donors and matched sibling donor allo-HCT in recently published data. ${ }^{53,17-149}$ One of the unanswered questions is whether post-transplant cyclophosphamide or anti-thymocyte globulin will be superior over others. Battipaglia et al. compared anti-thymocyte globulin with post-transplant cyclophosphamide in patients who had undergone HLA-mismatched unrelated donor transplantation. Results showed that post-transplant cyclophosphamide may have more favourable GVHD-free/relapse-free survival (37\% versus $21 \%, p<0.03$ ) outcomes without a survival advantage ( $56 \%$ versus $38 \%, p=0.07) .{ }^{150}$

In vivo T-cell depletion with anti-thymocyte globulin has been widely used in unrelated allo-HCT. Indications, type of anti-thymocyte globulin and dosing have been discussed in different studies. Donor type, conditioning regimen preferences, absolute lymphocyte count just before anti- thymocyte globulin infusion, ethnicity and GVHD prophylaxis preference appear to be good indicators of optimal anti-thymocyte globulin dose. ${ }^{151}$

\section{Graft-versus-host disease treatment}

Cumulative incidences of grade 3-4 acute GVHD range between 39\% and $59 \%$ according to the stem cell source, donor type and conditioning regimen. ${ }^{152}$ Although first-line treatment of GVHD is corticosteroids, second-line treatment remains challenging. In a recently published randomized phase III trial, ruxolitinib showed durable overall response rates (ORR) in corticosteroid-resistant acute GVHD (40\% versus $22 \%$, $p<0.001)$ with a tolerable safety profile compared with best available therapy. ${ }^{153}$ In a phase I study of pacritinib, a Janus kinase 1 inhibitor, $75 \%$ of the treatment-naive patients with acute GVHD had at least partial response at day 28. In steroid-refractory patients with acute GVHD, 28day ORR was $70.6 \%{ }^{154}$

Magenau et al. showed, with a prospective phase II study, that $\alpha 1$ antitrypsin, a serine protease inhibitor, may also have a role in the treatment of steroid-resistant acute GVHD. Treatment responses were sustainable in around two-thirds of the patients without any need for additional immunosuppression. ${ }^{155}$ The phase II/III, multicentre, randomized MODULAATE study of $\alpha 1$-antitrypsin in patients with acute GVHD is currently ongoing (ClinicalTrails.gov Identifier: NCT03805789). In a phase Ib trial, vedolizumab, as an anti- $\alpha 4 \beta 7$ integrin monoclonal antibody, showed an ORR in $79 \%(n=23)$ of patients; $28 \%(n=8)$ of patients had a complete remission. ${ }^{156}$ Recently, in a phase III trial, human mesenchymal stromal cells induced a more favourable ORR at day 100 in steroid-refractory patients with acute GVHD compared with a prespecified control group ( $70.4 \%$ versus $45 \%$, respectively; $p=0.0003$ ). ${ }^{157}$

Chronic GVHD is the major long-term consequence for allo-HCT survivors. ${ }^{158}$ In 2017, ibrutinib became the first US Food and Drug Administration (FDA)-approved drug approved for the treatment of chronic GVHD, in which patients failed with one or more lines of treatment. Ibrutinib is a selective inhibitor of Bruton's tyrosine kinase proteins and interleukin-2 inducible kinase, which has a role in T-cell activation. ${ }^{159}$ Miklos et al. conducted a phase Ib/Il study for testing the safety and efficacy of ibrutinib in patients with chronic GVHD who were non-responders to corticosteroid therapy and at least one line of therapy. The ORR was $67 \%$, with a complete remission rate of $21 \%$ and a partial response rate of $45 \% .{ }^{160}$

Graft failure is a substantial handicap in allo-HCT. Growth factors for tri-lineage, such as eltrombopag, recombinant human erythropoietin, and granulocyte stimulating agents, can be used successfully in the treatment of graft failure. ${ }^{161,162} \mathrm{~A}$ second allo-HCT can also be a solution. ${ }^{163}$

\section{Supportive care}

Infection is the leading cause of mortality during allo-HCT, especially in the early post-transplantation period. ${ }^{164}$ Not only is there an increased risk of bacterial infections, but also fungal and viral infections. ${ }^{165}$ Cytomegalovirus reactivation has been associated with poor allo-HCT outcomes and can induce graft failure or non-relapse mortality. ${ }^{156,166}$ Cytomegalovirus treatment may also result in myelosuppression as an adverse event.

Letermovir, an antiviral drug that inhibits the subunit of UL56 in the terminase complex that is essential for viral replication, has been approved for prophylaxis of cytomegalovirus by the FDA. ${ }^{167}$ In a multicentre phase III trial, prophylactic letermovir resulted in a lower 
reactivation rate and all-cause mortality compared with placebo without prominent myelosuppression. ${ }^{168}$ Maribavir is another antiviral drug active against cytomegalovirus infections, even in ganciclovir-, foscarnet- or cidofovir-resistant strains. ${ }^{169}$ Maertens et al. investigated the efficacy of maribavir $400 \mathrm{mg}, 800 \mathrm{mg}$ and 1,200 mg (by mouth, twice daily) on cytomegalovirus reactivation compared with valganciclovir in recipients of solid organ transplantation or allo-HCT in a phase II, randomized, doseranging study. Results showed similar response rates between maribavir treatment and the valganciclovir, and between the three maribavir dosing groups. Severe adverse event rates were higher in the maribavir groups $(44 \% \text { versus } 32 \%)^{170}$

In conclusion, in recent years, there has been promising advancement in the state of art for allo-HCT regarding GVHD prophylaxis and treatment. Improvements have also been seen in optimal conditioning regimens, novel HLA typing methods, more available alternative donor sources and supportive care. For the vast majority of the haematologic diseases, alloHCT seems to remain the only curative therapeutic option. $\square$
1. Chakraverty R, Eom H-S, Sachs J, et al. Host MHC class II+ antigen-presenting cells and $\mathrm{CD} 4$ cells are required for $\mathrm{CD} 8$ mediated graft-versus-leukemia responses following delayed mediated graft-versus-leukemia responses following

2. Traversari $C$, van der Bruggen $P$, Luescher I, et al. A nonapeptide encoded by human gene MAGE- 1 is recognized on HLA-A1 by cytolytic T lymphocytes directed against tumor antigen MZ2-E. Exp Med. 1992:176:1453-7.

3. Fujiwara $\mathrm{H}, \mathrm{El}$ Ouriaghli F, Grube $\mathrm{M}$, et al. Identification and in vitro expansion of $\mathrm{CD} 4+$ and $\mathrm{CD} 8+\mathrm{T}$ cells specific for human neutrophil elastase. Blood. 2004;103:3076-83.

4. Anguille S, Van Tendeloo V, Berneman Z. Leukemia-associated antigens and their relevance to the immunotherapy of acute myeloid leukemia. Leukemia. 2012;26:2186-96.

5. De Bueger M, Bakker A, Van Rood J, et al. Tissue distribution of human minor histocompatibility antigens Ubiquitous versus restricted tissue distribution indicates heterogeneity amon restric human cytotoxic Tlymphocy

6. Marijt WE, Heemskerk MH, Kloosterboer FM, et al. Hematopoiesis-restricted minor histocompatibility antigens HA-1-or HA-2-specific T cells can induce complete remissions of relapsed leukemia. PNAS. 2003;100:2742-7.

7. Kolb $\mathrm{H}-\mathrm{J}$, Schattenberg A, Goldman JM, et al. European Group for Blood and Marrow Transplantation Working Party Chronic Leukemia. Graft-versus-leukemia effect of donor lymphocyte transfusions in marrow grafted patients. Blood. 1995;86:2041-50.

8. Zorn E, Wang $\mathrm{KS}$, Hochberg EP, et al. Infusion of CD4+ donor lymphocytes induces the expansion of CD8+ donor T cells with cytolytic activity directed against recipient hematopoietic cells. Clin Cancer Res. 2002;8:2052-60

9. Horowitz MM, Gale RP, Sondel PM, et al. Graft-versusleukemia reactions after bone marrow transplantation. Blood. 1990;75:555-62.

10. Guglielmi C, Arcese W, Dazzi F, et al. Donor lymphocyte infusion for relapsed chronic myelogenous leukemia: prognostic relevance of the initial cell dose. Blood. 2002;100:397-405.
Dazzi F, Szydlo R, Craddock C, et al. Comparison of single-dose

11. Dazzi F, Szydlo R, Craddock C, et al. Comparison of single-dose
and escalating-dose regimens of donor lymphocyte infusion for relapse after allografting for chronic myeloid leukemia. Blood. 2000;95:67-7

12. Schmid C, Labopin M, Nagler A, et al. Donor lymphocyte infusion in the treatment of first hematological relapse after allogeneic stem-cell transplantation in adults with acute myeloid leukemia: a retrospective risk factors analysis and comparison with other strategies by the EBMT Acute Leukemia Working Party. J Clin Oncol. 2007;25:4938-45.

13. Dazzi F, Szydlo RM, Cross NC, et al. Durability of responses following donor lymphocyte infusions for patients who relapse after allogeneic stem cell transplantation for chronic myeloid after allogeneic stem cell transpla

14. Johnson BD, Drobyski WR, Truitt RL. Delayed infusion of normal donor cells after MHC-matched bone marrow transplantation provides an antileukemia reaction without graft-versus-host disease. Bone Marrow Transplant. 1993;11:329-36.

5. Gratwohl A, Pasquini MC, Aljurf M, et al. One million haemopoietic stem-cell transplants: a retrospective observational study. Lancet Haematol. 2015;2:e91-100.

16. Gooley TA, Chien JW, Pergam SA, et al. Reduced mortality after allogeneic hematopoietic-cell transplantation. N Engl J Med. 2010;363:2091-101.

17. Sette $A$, Buus $S$, Colon $S$, et al. Structural characteristics of an antigen required for its interaction with la and recognition by $\mathrm{T}$ cells. Nature. 1987:328:395-9.

18. Angelini $G$. De Preval C, Gorski J, Mach B. High-resolution analysis of the human HLA-DR polymorphism by hybridization with sequence-specific oligonucleotide probes Proc Natl Acad with sequence-specific oligon
SCi USA. 1986;83:4489-93.

19. Bunce M, Taylor CJ, Welsh KI. Rapid HLA-DQB typing by eight polymerase chain reaction amplifications with sequencespecific primers (PCR-SSP). Hum Immunol. 1993;37:201-6.

20. Santamaria P, Lindstrom AL, Boyce-Jacino MT, et al. HLA class I sequence-based typing. Hum Immunol. 1993;37:39-50.

21. Barone JC, Saito K, Beutner K, et al. HLA-genotyping of clinical specimens using Ion Torrent-based NGS. Hum Immunol. 2015;76:903-9.

22. Gabriel C, Danzer M, Hackl C, et al. Rapid high-throughput human leukocyte antigen typing by massively parallel pyrosequencing for high-resolution allele identification. Hum Immunol. 2009:70:960-4.

23. Weimer ET, Montgomery M. Petraroia R, et al. Performance characteristics and validation of next-generation sequencing for human leucocyte antigen typing. J Mol Diagn. 2016;18:66875.

24. Gandhi MJ, Ferriola D, Lind C, et al. Assessing a single targeted next generation sequencing for human leukocyte antigen typing protocol for interoperability, as performed by users with variable experience. Hum Immunol. 2017;78:642-8.

25. Wittig M, Anmarkrud JA, Kässens JC, et al. Development of a high-resolution NGS-based HLA-typing and analysis pipeline Nucleic Acids Res. 2015;43:e70.

26. Boegel S, Löwer M, Schäfer M, et al. HLA typing from RNA-Sec sequence reads. Genome Med. 2012;4:102.

27. Duke JL, Mosbruger TL, Ferriola D, et al. Resolving Miseqgenerated ambiguities in HLA-DPB1 typing by using the oxford Nanopore technology. J Mol Diagn. 2019;21:852-61.

28. Küçük C, Hu X, Gong Q, et al. Diagnostic and biologica significance of KIR expression profile determined by RNA-Seq in natural killer/T-cell lymphoma. Am J Pathol. 2016;186:1435-41.

29. Kröger $N$, Binder T, Zabelina T, et al. Low number of donor activating killer immunoglobulin-like receptors (KIR) genes but not KIR-ligand mismatch prevents relapse and improves disease-free survival in leukemia patients after in vivo T-cell depleted unrelated stem cell transplantation. Transplantation. 2006:82:1024-30.

30. Gragert L, Eapen M, Williams E, et al. HLA match likelihoods for hematopoietic stem-cell grafts in the US registry. N Eng/ J Med. 2014;371:339-48.

31. Dehn J, Spellman S, Hurley CK, et al. Selection of unrelated donors and cord blood units for hematopoietic cell transplantation: guidelines from the NMDP/CIBMTR. Blood. 2019;134:924-34

32. Spellman S, Bray R, Rosen-Bronson $\mathrm{S}$, et al. The detection of donor-directed, HLA-specific alloantibodies in recipients of unrelated hematopoietic cell transplantation is predictive of graft failure. Blood. 2010;115:2704-8

33. Crivello $P$, Zito L, Sizzano F, et al. The impact of amino acid variability on alloreactivity defines a functional distance predictive of permissive HLA-DPB1 mismatches in hematopoietic stem cell transplantation. Biol Blood Marrow Transplant 2015:21:233-41.

34. Crivello P, Heinold A, Rebmann V , et al. Functional distance between recipient and donor HLA-DPB1 determines nonpermissive mismatches in unrelated HCT. Blood. 2016:128:120-9.

35. Pidala J, Lee SJ, Ahn KW, et al. Nonpermissive HLA-DPB1 mismatch increases mortality after myeloablative unrelated allogeneic hematopoietic cell transplantation. Blood. 2014;124:2596-606

36. Arrieta-Bolaños E, Crivello P, Shaw BE, et al. In silico prediction of nonpermissive HLA-DPB1 mismatches in unrelated HCT by functional distance. Blood Adv. 2018;2:1773-83.

37. Morishima S, Shiina T, Suzuki S, et al. Evolutionary basis of HLADPB1 alleles affects acute GVHD in unrelated donor stem cell transplantation. Blood. 2018;131:808-17.

38. Gupta V, Tallman MS, He W, et al. Comparable survival after HLA-well-matched unrelated or matched sibling donor transplantation for acute myeloid leukemia in first remission with unfavorable cytogenetics at diagnosis. Blood 2010;116:1839-48.

39. Saber W, Opie S, Rizzo JD, et al. Outcomes after matched unrelated donor versus identical sibling hematopoietic cell transplantation in adults with acute myelogenous leukemia. Blood. 2012;119:3908-16.

40. Mielcarek M, Storer BE, Sandmaier BM, et al. Comparable outcomes after nonmyeloablative hematopoietic cell transplantation with unrelated and related donors. Biol Blood Marrow Transplant. 2007;13:1499-507.

41. Ho VT, Kim HT, Aldridge J, et al. Use of matched unrelated donors compared with matched related donors is associated with lower relapse and superior progression-free survival after reduced-intensity conditioning hematopoietic stem cell transplantation. Biol Blood Marrow Transplant. 2011;17:1196204.

42. Yao S, Hahn T, Zhang Y, et al. Unrelated donor allogeneic hematopoietic cell transplantation is underused as a curative therapy in eligible patients from the United States. Biol Blood Marrow Transplant. 2013;19:1459-64.

3. Besse K, Maiers M, Confer D, Albrecht M. On modeling human leukocyte antigen-identical sibling match probability for allogeneic hematopoietic cell transplantation: estimating the need for an unrelated donor source. Biol Blood Marrow Transplant. 2016:22:410-7.

44. Yakoub-Agha I, Mesnil F, Kuentz M, et al. Allogeneic marrow stem-cell transplantation from human leukocyte antigen-identical siblings versus human leukocyte antigenallelic-matched unrelated donors (10/10) in patients with standard-risk hematologic malignancy: a prospective study standard-risk hematologic malignancy: a prospective study from the French Society of Bone Marrow Transpli
Cell Therapy. I Clin Oncol. 2006;24:5695-702.

45. Arora $\mathrm{M}$, Weisdorf DJ, Spellman SR, et al. HLA-identical sibling compared with $8 / 8$ matched and mismatched unrelated dono bone marrow transplant for chronic phase chronic myeloid leukemia. J Clin Oncol. 2009;27:1644-52.

46. Woolfrey A, Lee SJ, Gooley TA, et al. HLA-allele matched unrelated donors compared to HLA-matched sibling donors: role of cell source and disease risk category. Biol Blood Marrow Transplant 2010:16:1382-7.

47. Schetelig J, Bornhäuser M, Schmid C, et al. Matched unrelated or matched sibling donors result in comparable survival after allogeneic stem-cell transplantation in elderly patients with acute myeloid leukemia: a report from the cooperative German Transplant Study Group. J Clin Oncol. 2008;26:5183-91.

48. Passweg JR, Baldomero $\mathrm{H}$, Bader $\mathrm{P}$, et al. Is the use of unrelated donor transplantation leveling off in Europe? The 2016 European Society for Blood and Marrow Transplant activity survey report. Bone Marrow Transplant. 2018;53:1139-48.

49. McCarthy Jr PL, Hahn T, Hassebroek A, et al. Trends in use of and survival after autologous hematopoietic cell transplantation in North America, 1995-2005: significant improvement in survival for lymphoma and myeloma during a period of increasing recipient age. Biol Blood Marrow Transplant. 2013;19:1116-23.

50. Debals-Gonthier M, Siani C, Faucher C, et al. Cost-effectiveness analysis of haploidentical vs matched unrelated allogeneic hematopoietic stem cells transplantation in patients older than 55 years. Bone Marrow Transplant. 2018;53:1096-104.

51. Arnold SD, Brazauskas R, He N, et al. The impact of donor type on outcomes and cost of allogeneic hematopoietic cell transplantation for pediatric leukemia: a merged center for international blood and marrow transplant research and pediatric health information system analysis. Biol Blood Marrow Transplant. 2020;26:1747-56.

52. Ciurea SO, Zhang M-J, Bacigalupo AA, et al. Haploidentical transplant with posttransplant cyclophosphamide vs matched unrelated donor transplant for acute myeloid leukemia. Blood. 2015:126:1033-40.

53. Di Stasi A, Milton DR, Poon L, et al. Similar transplantation outcomes for acute myeloid leukemia and myelodysplastic syndrome patients with haploidentical versus 10/10 human leukocyte antigen-matched unrelated and related Donors. Biol Blood Marrow Transplant. 2014;20:1975-81.

54. Martínez C, Gayoso J, Canals C, et al. Post-transplantation cyclophosphamide-based haploidentical transplantation as alternative to matched sibling or unrelated donor transplantation for Hodgkin lymphoma: a registry study of the Lymphoma Working Party of the European Society for Blood and Marrow Transplantation. J Clin Oncol. 2017:35:3425-32.

55. Burroughs LM, O'Donnell PV, Sandmaier BM, et al. Comparison of outcomes of HLA-matched related, unrelated, or HLAhaploidentical related hematopoietic cell transplantation following nonmyeloablative conditioning for relapsed or refractory Hodgkin lymphoma. Biol Blood Marrow Transplant. 2008:14:1279-87.

56. Anurathapan U, Hongeng S, Pakakasama S, et al. Hematopoietic stem cell transplantation for severe thalassemia patients from haploidentical donors using a novel conditioning regimen. Biol Blood Marrow Transplant. 2020;26:1106-12.

57. Gaziev J, Isgro A, Sodani P, et al. Haploidentical HSCT for hemoglobinopathies: improved outcomes with TCR $\alpha+/$ CD 19+ depleted grafts. Blood Adv. 2018;2:263-70.

58. Esteves I, Bonfim C, Pasquini R, et al. Haploidentical BMT and post-transplant Cy for severe aplastic anemia: a multicenter retrospective study. Bone Marrow Transplant. 2015;50:685-9.

59. Xu L, Liu K, Liu D, et al. A novel protocol for haploidentical hematopoietic SCT without in vitro T-cell depletion in the treatment of severe acquired aplastic anemia. Bone Marrow Transplant. 2012;47:1507-12.

60. Xu L, Zhang X, Wang F, et al. Haploidentical transplantation for pediatric patients with acquired severe aplastic anemia. Bone Marrow Transplant. 2017:52:381-7.

61. ElGohary G, El Fakih R, de Latour R, et al. Haploidentical hematopoietic stem cell transplantation in aplastic anemia: a systematic review and meta-analysis of clinical outcome on behalf of the severe aplastic anemia working party of the
European group for blood and marrow transplantation (SAAWP of EBMT). Bone Marrow Transplant. 2020;55:1906-17.

62. Neelapu SS, Locke FL, Bartlett NL, et al. Axicabtagene ciloleucel CAR T-cell therapy in refractory large B-cell lymphoma. N Engl J Med. 2017:377:2531-44.

63. Schuster SJ, Bishop MR, Tam CS, et al. Tisagenlecleucel in adult relapsed or refractory diffuse large B-cell lymphoma. N Eng/ J Med. 2019;380:45-56

64. Dreger P, Sureda A, Ahn KW, et al. PTCy-based haploidentical vs matched related or unrelated donor reduced-intensity conditioning transplant for DLBCL. Blood AdV. 2019:3:360-9.

65. Kanate AS, Mussetti A, Kharfan-Dabaja MA, et al. Reducedintensity transplantation for lymphomas using haploidentical related donors vs HLA-matched unrelated donors. Blood. 2016;127:938-47. 
66. Ahmed S, Kanakry JA, Ahn KW, et al. Lower graft-versus-host disease and relapse risk in post-transplant cyclophosphamidebased haploidentical versus matched sibling donor reducedintensity conditioning transplant for hodgkin lymphoma. Biol Blood Marrow Transplant 2019:25:1859-68.

67. Rocha V, Cornish J, Sievers EL, et al. Comparison of outcomes of unrelated bone marrow and umbilical cord blood transplants in children with acute leukemia. Blood. 2001;97:2962-71.

68. Barker JN, Scaradavou A, Stevens CE. Combined effect of total nucleated cell dose and HLA match on transplantation outcome in 1061 cord blood recipients with hematologic malignancies. Blood. 2010;115:1843-9.

69. Regan DM, Wofford JD, Wall DA. Comparison of cord blood thawing methods on cell recovery, potency, and infusion. Transfusion. 2010;50:2670-5.

70. Wagner Jr JE, Brunstein CG, Boitano AE, et al. Phase I/I trial of StemRegenin-1 expanded umbilical cord blood hematopoietic stem cells supports testing as a stand-alone graft. Cell Stem Cell. 2016;18:144-55

71. Codispoti B, Rinaldo N, Chiarella E, et al. Recombinant TAT $\mathrm{BMI}-1$ fusion protein induces ex vivo expansion of human umbilical cord blood-derived hematopoietic stem cells. Oncotarget. 2017;8:43782-98.

72. Horwitz ME, Chao NJ, Rizzieri DA, et al. Umbilical cord blood expansion with nicotinamide provides long-term multilineage engraftment. J Clin Invest. 2014;124:3121-8.

73. Marquez-Curtis LA, Qiu Y, Xu A, Janowska-Wieczorek A. Migration, proliferation, and differentiation of cord blood mesenchymal stromal cells treated with histone deacetylase inhibitor valproic acid. Stem Cells Int. 2014;2014:610495.

74. Farag SS, Nelson R, Cairo MS, et al. High-dose sitagliptin for systemic inhibition of dipeptidylpeptidase-4 to enhance engraftment of single cord umbilical cord blood transplantation Oncotarget. 2017:8:110350-7.

75. Roy S, Tripathy M, Mathur N, et al. Hypoxia improves expansion potential of human cord blood-derived hematopoietic stem cells and marrow repopulation efficiency. Eur $J$ Haematol. 2012;88:396-405

76. Ruggeri A, Sanz G, Bittencourt H, et al. Comparison of outcomes after single or double cord blood transplantation in adults with acute leukemia using different types of myeloablative conditioning regimen, a retrospective study on behalf of Eurocord and the Acute Leukemia Working Party of EBMT. Leukemia. 2014;28:779-86.

77. Liu H, Rich ES, Godley L, et al. Reduced-intensity conditioning with combined haploidentical and cord blood transplantation results in rapid engraftment, low GVHD, and durable remissions. Blood. 2011;118:6438-45.

78. Kwon M, Bautista G, Balsalobre P, et al. Haplo-cord transplantation using CD34+ cells from a third-party donor to speed engraftment in high-risk patients with hematologic disorders. Biol Blood Marrow Transplant. 2014;20:2015-22.

79. Muffly L, Pasquini MC, Martens M, et al. Increasing use of allogeneic hematopoietic cell transplantation (HCT) in patients age 70 years and older: a CIBMTR study of trends and outcomes. Biol Blood Marrow Transplant. 2016;22:S68-9.

80. Schneidawind D, Federmann B, Buechele C, et al. Reducedintensity conditioning with fludarabine and busulfan for allogeneic hematopoietic cell transplantation in elderly or infirm patients with advanced myeloid malignancies. Ann Hematol. 2016;95:115-24.

81. Lim Z, Brand R, Martino R, et al. Allogeneic hematopoietic stem-cell transplantation for patients 50 years or older with myelodysplastic syndromes or secondary acute myeloid leukemia. J Clin Oncol. 2010:28:405-11.

82. Scott BL, Pasquini MC, Logan BR, et al. Myeloablative versus reduced-intensity hematopoietic cell transplantation for acute myeloid leukemia and myelodysplastic syndromes. J Clin Oncol. 2017;35:1154-61

83. Fasslrinner F, Schetelig J, Burchert A, et al. Long-term efficacy of reduced-intensity versus myeloablative conditioning before allogeneic haemopoietic cell transplantation in patients with acute myeloid leukaemia in first complete remission: retrospective follow-up of an open-label, randomised phase 3 trial. Lancet Haematol. 2018;5:e161-9.

84. Ciurea SO, Kongtim P, Varma A, et al. Is there an optimal conditioning for older patients with AML receiving allogeneic hematopoietic cell transplantation? Blood. 2020:135:449-52.

85. Ali MM, Abounader DM, Rybicki LA, et al. Comparative effectiveness of busulfan and fludarabine versus fludarabine and 400 cgy total body irradiation conditioning regimens for acute myeloid leukemia/myelodysplastic syndrome. Biol Blood Marrow Transplant. 2017:23:776-81.

86. Clift RA, Buckner CD, Thomas ED, et al. Marrow transplantation for chronic myeloid leukemia: a randomized study comparing cyclophosphamide and total body irradiation with busulfan and cyclophosphamide. Blood. 1994:84:2036-43.

87. Dix C, LO TH, Clark G, Abadir E. Measurable residual disease in acute myeloid leukemia using flow cytometry: A review of where we are and where we are going. J Clin Med 2020;9:1714

88. Thol F, Gabdoulline $R$, Liebich $A$, et al. Measurable residual disease monitoring by NGS before allogeneic hematopoietic cell transplantation in AML. Blood. 2018;132:1703-13.

89. Araki D, Wood BL, Othus M, et al. Allogeneic hematopoietic cell transplantation for acute myeloid leukemia: time to move toward a minimal residual disease-based definition of complete remission? J Clin Oncol. 2016:34:329-36.

90. Jongen-Lavrencic M, Grob T, Hanekamp D, et al. Molecular minimal residual disease in acute myeloid leukemia. N Eng/ Med. 2018;378:1189-99.

91. Venditti A, Piciocchi A, Candoni A, et al. GIMEMA AML1310 trial of risk-adapted, MRD-directed therapy for young adults with newly diagnosed acute myeloid leukemia. Blood. 2019;134:935-45.

92. Shah MV, Jorgensen JL, Saliba RM, et al. Early post-transplant minimal residual disease assessment improves risk stratification in acute myeloid leukemia. Biol Blood Marrow Transplant. 2018:24:1514-20.

93. Platzbecker U, Middeke JM, Sockel K et al. Measurable residual disease-guided treatment with azacitidine to prevent haematological relapse in patients with myelodysplastic syndrome and acute myeloid leukaemia (RELAZA2): an openlabel, multicentre, phase 2 trial. Lancet Oncol. 2018;19:1668-79.

4. Burchert A, Bug G, Fritz LV, et al. Sorafenib maintenance after allogeneic hematopoietic stem cell transplantation for acute myeloid leukemia with FLT3-Internal tandem duplication mutation (SORMAIN). J Clin Oncol. 2020;38:2993-3002.

95. Schlenk RF, Weber D, Fiedler W, et al. Midostaurin added to chemotherapy and continued single-agent maintenance therapy in acute myeloid leukemia with FLT3-ITD. Blood. 2019;133:840-51.

96. Levis MJ, Hamadani M, Logan B, et al. A phase 3, trial of gilteritinib, as maintenance therapy after allogeneic hematopoietic stem cell transplantation in patients

7. Mohty M, Labopin M, Volin L, et al. Reduced-intensity versus conventional myeloablative conditioning allogeneic stem cell transplantation for patients with acute lymphoblastic leukemia:
a retrospective study from the European Group for Blood and a retrospective study from the European Group for

98. Marks DI, Wang T, Pérez WS, et al. The outcome of full-intensity and reduced-intensity conditioning matched sibling or unrelated donor transplantation in adults with Philadelphia chromosome-negative acute lymphoblastic leukemia in first and second complete remission. Blood. 2010;116:366-74.

99. Kebriaei P, Anasetti C, Zhang M-J, et al. Intravenous busulfan compared with total body irradiation pretransplant conditioning for adults with acute lymphoblastic leukemia. Biol Blood Marrow Transplant. 2018;24:726-33.

100. Park H, Byun JM, Koh Y, et al. Comparison of different conditioning regimens in allogeneic hematopoietic stem-cell transplantation shows superiority of total body irradiation-based regimen for younger patients with acute leukemia: a nationwide study. Clin Lymphoma Myeloma Leuk. 2019;19:e605-15.

01. Sakellari I, Gavriilaki E, Chatziioannou K, et al. Long-term outcomes of total body irradiation plus cyclophosphamide versus busulfan plus cyclophosphamide as conditioning regimen for acute lymphoblastic leukemia: a comparative study. Ann Hematol. 2018;97:1987-94.

02. Czyz A, Labopin M, Giebel S, et al. Cyclophosphamide versus etoposide in combination with total body irradiation as conditioning regimen for adult patients with Ph-negative acute lymphoblastic leukemia undergoing allogeneic stem cell transplant: On behalf of the ALWP of the European Society for Blood and Marrow Transplantation. Am J Hematol. 2018:93:778-85.

103. Mitsuhashi K, Kako S, Shigematsu A, et al. Comparison of cyclophosphamide combined with total body irradiation, oral busulfan, or intravenous busulfan for allogeneic hematopoietic cell transplantation in adults with acute lymphoblastic

leukemia. Biol Blood Marrow Transplant. 2016;22:2194-200.
104. Giebel S, Marks DI, Boissel N, et al. Hematopoietic stem cell transplantation for adults with Philadelphia chromosomenegative acute lymphoblastic leukemia in first remission: a position statement of the European Working Group for Adult Acute Lymphoblastic Leukemia (EWALL) and the Acute Leukemia Working Party of the European Society for Blood and Marrow Transplantation (EBMT). Bone Marrow Transplant. 2019;54:798-809

105. Pavlú J, Labopin M, Niittyvuopio R, et al. Measurable residua disease at myeloablative allogeneic transplantation in adults with acute lymphoblastic leukemia: a retrospective registry study on 2780 patients from the acute leukemia working party of the EBMT. I Hematol Oncol. 2019:12:108.

106. Modvig S, Madsen H, Siitonen S, et al. Minimal residual disease quantification by flow cytometry provides reliable risk stratification in T-cell acute lymphoblastic leukemia. Leukemia. 2019;33:1324-36

107. Dhédin N, Huynh A, Maury S, et al. Role of allogeneic stem cell transplantation in adult patients with $\mathrm{Ph}$-negative acute lymphoblastic leukemia. Blood. 2015;125:2486-96.

08. Li S-Q, Fan Q-Z, Xu L-P, et al. Different effects of pretransplantation measurable residual disease on outcomes according to transplant modality in patients with Philadelphia chromosome positive ALL. Front Oncol. 2020;10:320.

109. Bacher U, Klyuchnikov E, Le-Rademacher J, et al. Conditioning regimens for allotransplants for diffuse large B-cell lymphoma: myeloablative or reduced intensity? Blood 2012:120:4256-62

110. Armand P, Kim HT, Ho VT, et al. Allogeneic transplantation with reduced-intensity conditioning for Hodgkin and non-Hodgkin lymphoma: importance of histology for outcome. Biol Blood Marrow Transplant. 2008:14:418-25.

111. Kharfan-Dabaja MA, Reljic T, El-Asmar J, et al. Reduced-intensity or myeloablative allogeneic hematopoietic cell transplantation for mantle cell lymphoma: a systematic review. Future Oncol. 2016;12:2631-42.

112. Kharfan-Dabaja MA, Moukalled N, Reljic T, et al. Reduced intensity is preferred over myeloablative conditioning allogeneic HCT in chronic lymphocytic leukemia whenever indicated: a systematic review/meta-analysis. Hematol Oncol Stem Cell Ther. 2018;11:53-64.

113. Andersen NS, Bornhaeuser M, Gramatzki M, et al. Reduced intensity conditioning regimens including alkylating chemotherapy do not alter survival outcomes after allogeneic hematopoietic cell transplantation in chronic lymphocytic leukemia compared to low-intensity non-myeloablative Conditioning. J Cancer Res Clin Oncol. 2019;145:2823-34.
Barrett AJ, Ito S. The role of stem cell transplantation for

4. Barrett AJ, Ito S. The role of stem cell transplantation for
chronic myelogenous leukemia in the 21st century. Blood. chronic myelogen

15. Das M, Saikia T, Advani S, Parikh P, Tawde S. Use of a reduced-

intensity conditioning regimen for allogeneic transplantation in patients with chronic myeloid leukemia. Bone Marrow Transplant. 2003:32:125-9.

116. Topcuoglu P, Arat M, Ozcan M, et al. Case-matched comparison with standard versus reduced intensity conditioning regimen in chronic myeloid leukemia patients. Ann Hematol. 2012;91:577-86.

117. Chhabra S, Ahn KW, Hu Z-H, et al. Myeloablative vs reducedintensity conditioning allogeneic hematopoietic cell transplantation for chronic myeloid leukemia. Blood Adv. 2018;2:2922-36

118. Hernández-Boluda JC, Pereira A, Alvarez-Larran A, et al. Predicting survival after allogeneic hematopoietic cell transplantation in myelofibrosis: performance of the myelofibrosis transplant scoring system (MTSS) and development of a new prognostic model. Biol Blood Marrow Transplant. 2020;26:2237-44.

119. Rondelli D, Goldberg JD, Isola L, et al. MPD-RC 101 prospective study of reduced-intensity allogeneic hematopoietic stem cell transplantation in patients with myelofibrosis. Blood. 2014;124:1183-91.

120. Jain T, Kunze KL, Temkit M, et al. Comparison of reduced intensity conditioning regimens used in patients undergoing hematopoietic stem cell transplantation for myelofibrosis. Bone Marrow Transplant. 2019;54:204-11.

121. Kröger N, Holler E, Kobbe G, et al. Allogeneic stem cell transplantation after reduced-intensity conditioning in patients with myelofibrosis: a prospective, multicenter study of the Chronic Leukemia Working Party of the European Group for Blood and Marrow Transplantation. Blood. 2009:114:5264-70.

122. Storb R, Etzioni R, Anasetti C, et al. Cyclophosphamide combined with antithymocyte globulin in preparation for allogeneic marrow transplants in patients with aplastic anemia. Blood. 1994;84:941-9.

123. Resnick IB, Aker M, Shapira MY, et al. Allogeneic stem cell transplantation for severe acquired aplastic anaemia using a fludarabine-based preparative regimen. Br I Haematol. 2006;133:649-54

124. Maury S, Bacigalupo A, Anderlini P, et al. Improved outcome of patients older than 30 years receiving HLA-identical sibling hematopoietic stem cell transplantation for severe acquired aplastic anemia using fludarabine-based conditioning: a comparison with conventional conditioning regimen. Haematologica. 2009:94:1312-5.

125. Lucarelli G, Galimberti M, Polchi P, et al. Bone marrow transplantation in patients with thalassemia. N Eng/ J Med. 1990;322:417-21

126. Mathews V, George B, Viswabandya A, et al. Improved clinical outcomes of high risk $\beta$ thalassemia major patients undergoing a HLA matched related allogeneic stem cell transplant with a treosulfan based conditioning regimen and peripheral blood treosulfan based conditioning regimen and

127. Chhabra A, Ring AM, Weiskopf $K$, et al. Hematopoietic stem cell transplantation in immunocompetent hosts without radiation or chemotherapy. Sci Trans/ Med. 2016;8:351ra105.

128. Gennery AR, Slatter MA, Grandin L, et al. Transplantation of hematopoietic stem cells and long-term survival for primary immunodeficiencies in Europe: entering a new century, do we do better? J Allergy Clin Immunol. 2010;126:602-10.e1-11.

129. Dvorak CC, Hassan A, Slatter MA, et al. Comparison of outcomes of hematopoietic stem cell transplantation without chemotherapy conditioning by using matched sibling and unrelated donors for treatment of severe combined immunodeficiency. J Allergy Clin Immunol. 2014;134:935-43. e15.

130. Shaw P, Shizuru J, Hoenig M, Veys P. Conditioning perspectives for primary immunodeficiency stem cell transplants. Front Pediatr. 2019;7:434.

131. Hartman A, Williams S, Dillon J. Survival, disease-free survival and adverse effects of conditioning for allogeneic bone marrow transplantation with busulfan/cyclophosphamide vs total body irradiation:

132. Vo P, Gooley TA, Rajendran JG, et al. Yttrium-90-labeled antiCD45 antibody followed by a reduced-intensity hematopoietic cell transplantation for patients with relapsed/refractory leukemia or myelodysplasia. Haematologica. 2020;105:1731-7.

133. Bouabdallah K, Furst S, Asselineau J, et al. 90Y-ibritumomab tiuxetan, fludarabine, busulfan and antithymocyte globulin reduced-intensity allogeneic transplant conditioning for patients with advanced and high-risk B-cell lymphomas. Ann Oncol. 2015;26:193-8.

134. Storb R, Deeg $\mathrm{HJ}$, Pepe $\mathrm{M}$, et al. Methotrexate and cyclosporine versus cyclosporine alone for prophylaxis of graft-versus- 
transplantation. Transplantation. 2020;104:428-36.

140. Niederwieser D, Maris M, Shizuru JA, et al. Low-dose total body irradiation (TBI) and fludarabine followed by hematopoietic cell transplantation (HCT) from HLA-matched or mismatched unrelated donors and postgrafting immunosuppression with cyclosporine and mycophenolate mofetil (MMF) can induce durable complete chimerism and sustained remissions in durable complete chimerism and sustained remissions in
patients with hematological diseases. Blood. 2003;101:1620-9

141. Ngwube A, Shah N, Godder K, et al. Abatacept is effective as GVHD prophylaxis in unrelated donor stem cell transplantation for children with severe sickle cell disease. Blood Adv. 2020;4:3894-9.

142. Khandelwal P, Yeh RF, Yu L, et al. Graft versus host disease prophylaxis with abatacept reduces severe acute graft versus host disease in allogeneic hematopoietic stem cell transplant for beta thalassemia major with busulfan, fludarabine, and thiotepa. Transplantation. 2021;10:891-6.

143. Reshef R, Ganetsky A, Acosta EP, et al. Extended CCR5 blockade for graft-versus-host disease prophylaxis improves outcomes of reduced-intensity unrelated donor hematopoietic cell transplantation: a phase II clinical trial. Biol Blood Marrow transplantation: a phase II c1

144. Morata-Tarifa C, Macías-Sánchez MDM, Gutiérrez-Pizarraya A, Sanchez-Pernaute R. Mesenchymal stromal cells for the prophylaxis and treatment of graft-versus-host disease-a metaanalysis. Stem Cell Res Ther. 2020;11:64.

145. Morozova EV, Barabanshikova MV, Moiseev IS, et al. A prospective pilot study of graft-versus-host disease prophylaxis with post-transplantation cyclophosphamide and ruxolitinib in patients with myelofibrosis. Acta Haematol. 2021;144:158-65.

146. Luznik $L$, Jalla $S$, Engstrom $L W$, et al. Durable engraftment of major histocompatibility complex-incompatible cells after nonmyeloablative conditioning with fludarabine, low-dose total body irradiation, and posttransplantation cyclophosphamide. Blood. 2001:98:3456-64.

147. Rashidi A, Slade M, DiPersio J, et al. Post-transplant high-dose cyclophosphamide after HLA-matched vs haploidentical
cystical cyclophosphamide after HLA-matched vs haploidentical
hematopoietic cell transplantation for AML. Bone Marrow Transplant. 2016:51:1561-4.

148. Kasamon YL, Ambinder RF, Fuchs EJ, et al. Prospective study of nonmyeloablative, HLA-mismatched unrelated BMT with high-dose posttransplantation cyclophosphamide. Blood Adv. 2017:1:288-92.
149. Ghosh N, Karmali R, Rocha V, et al. Reduced-intensity transplantation for lymphomas using haploidentical related donors versus HLA-matched sibling donors: a Center for International Blood and Marrow Transplant Research analysis. International Blood and Marrow

150. Battipaglia G, Labopin M, Kröger N, et al. Posttransplant cyclophosphamide vs antithymocyte globulin in HLAmismatched unrelated donor transplantation. Blood. 2019;134:892-9.

151. Shichijo T, Fuji S, Nagler A, et al. Personalizing rabbit antithymocyte globulin therapy for prevention of graft-versus-hos disease after allogeneic hematopoietic cell transplantation: is there an optimal dose? Bone Marrow Transplant 2020;55:505-22.

152. Jagasia $\mathrm{M}$, Arora $\mathrm{M}$, Flowers $\mathrm{ME}$, et al. Risk factors for acute GVHD and survival after hematopoietic cell transplantation. Blood. 2012;119:296-307.

153. Zeiser R, von Bubnoff N, Butler J, et al. Ruxolitinib for glucocorticoid-refractory acute graft-versus-host disease. N glucocorticoid-refractory acute,
Eng/ J Med. 2020;382:1800-10.

154. Schroeder MA, Khoury HJ, Jagasia M, et al. A phase 1 trial of itacitinib, a selective JAK1 inhibitor, in patients with acute graftversus-host disease. Blood Adv. 2020;4:1656-69.

55. Magenau JM, Goldstein SC, Peltier D, et al. a1-Antitrypsin infusion for treatment of steroid-resistant acute graft-versushost disease. Blood. 2018;131:1372-9.

156. Danylesko I, Bukauskas A, Paulson M, et al. Anti- $\alpha 4 \beta 7$ integrin monoclonal antibody (vedolizumab) for the treatment of steroid-resistant severe intestinal acute graft-versus-host disease. Bone Marrow Transplant. 2019;54:987-93.

157. Kurtzberg J, Abdel-Azim H, Carpenter P, et al. A phase 3 , single-arm, prospective study of remestemcel-I, ex vivo cultureexpanded adult human mesenchymal stromal cells for the treatment of pediatric patients who failed to respond to steroid treatment for acute graft-versus-host disease. Biol Blood Marrow Transplant. 2020;26:845-54.

158. Sun C-L, Kersey JH, Francisco L, et al. Burden of morbidity in $10+$ year survivors of hematopoietic cell transplantation: report from the bone marrow transplantation survivor study. Biol Blood Marrow Transplant. 2013;19:1073-80.

159. Dubovsky JA, Beckwith KA, Natarajan G, et al. Ibrutinib is an irreversible molecular inhibitor of ITK driving a Th1-selective pressure in T lymphocytes. Blood. 2013;122:2539-49.
160. Miklos D, Cutler CS, Arora M, et al. Ibrutinib for chronic graft-versus-host disease after failure of prior therapy. Blood. 2017; 130:2243-50

161. Tanaka T, Inamoto Y, Yamashita T, et al. Eltrombopag for treatment of thrombocytopenia after allogeneic hematopoietic cell transplantation Biol Blood Marrow Transplant. 2016:22:919-24

162. Jaspers A, Baron F, Willems $E$, et al. Erythropoietin therapy after allogeneic hematopoietic cell transplantation: a prospective, randomized trial. Blood. 2014;124:33-41.

163. Schriber J, Agovi M-A, Ho V, et al. Second unrelated donor hematopoietic cell transplantation for primary graft failure. Biol Blood Marrow Transplant. 2010;16:1099-106.

164. Gratwohl A, Brand R, Frassoni F, et al. Cause of death after allogeneic haematopoietic stem cell transplantation (HSC in early leukemias: an EBMT analysis of lethal infectious complications and changes over calendar time. Bone Marrow Transplant. 2005:36:757-69.

165. Kontoyiannis DP, Marr KA, Park BJ, et al. Prospective surveillance for invasive fungal infections in hematopoietic stem cell transplant recipients, 2001-2006: overview of stem cell transplant recipients, 2001-2006: Overview of the Transplant-Associated Infection Surveillance Network
(TRANSNET) Database. Clin Infect Dis. 2010;50:1091-100.

66. Teira P, Battiwalla M, Ramanathan M, et al. Early cytomegalovirus reactivation remains associated with increased transplant-related mortality in the current era: a CIBMTR analysis. Blood. 2016;127:2427-38.

167. Goldner T, Hewlett G, Ettischer N, et al. The novel anticytomegalovirus compound AIC246 (Letermovir) inhibits human cytomegalovirus replication through a specific antiviral mechanism that involves the viral terminase. J Virol. 2011;85:10884-93.

168. Marty FM, Ljungman P, Chemaly RF, et al. Letermovir prophylaxis for cytomegalovirus in hematopoietic-cell transplantation. N Eng/ J Med. 2017:377:2433-44.

169. Drew WL, Miner RC, Marousek GI, Chou S. Maribavir sensitivity of cytomegalovirus isolates resistant to ganciclovir, cidofovir or foscarnet. J Virol. 2006;37:124-7.

170. Maertens J, Cordonnier C, Jaksch P, et al. Maribavir for preemptive treatment of cytomegalovirus reactivation. $\mathrm{NEng/J}$ Med. 2019;381:1136-47. 